\title{
Analysis of Motivation Triggers in Interactive Digital Reading for Children
}

\author{
Ming-Chieh Hsu \\ Department of Information Communication, \\ Yuan Ze University \\ Taiwan
}

\begin{abstract}
Electronic teaching materials for children's books are viewed as playful, interactive, and with self learning adaptation functions to stimulate learner's motivation and enhance learning. The digital books are operated with the help of a touch pen that points to the page to make repeated sounds. Each pinpoint can make different vocalization; the interactive questions and answers can be incorporated into the design to produce different sounds that enhance the learning experiences. This study targets second and third graders who switched from reading books with an adult to reading independently, and explores whether interactive books stimulate children's interests in reading. Related studies have shown that four important factors play a major role in motivating children to read. These factors include the ability to hold a child's attention, providing enjoyment, playfulness, and a sense of participation. These factors are also crucial in digital reading, therefore, this study uses an experimental method to prove these books can increase a child's reading interest. The results have shown that interactive digital children's books are significantly better than paper books in keeping a child's attention and fostering interest in reading. The visual and audio functions of interactive digital books provide children with enjoyment and interactivity which allow children to feel like they are a part of the story.
\end{abstract}

\section{Introduction}

The natural occurrence of a word, the characteristics of one's reading style, as well as the amount of browsing and repeated reading of a book are all important contributions to the process of developing vocabularies for children [1]. With the prevalence of electronic media in the information explosion era, children's reading ability is going downhill at an accelerating speed. According to the 2010 survey on recreational activities of children in Taiwan, reading is less than $10 \%$ of a child's daily activities, far less than watching TV and using the computer. Reading for kids has become more multifaceted, how to establish a child's treasure house of knowledge and guide them to read has become an important issue [2]. We still need to study whether education in the form of entertainment can bring learning outcomes. Through the interactive

\author{
Chih-Ping Chen \\ Discipline of Marketing, \\ College of Management, \\ Yuan Ze University \\ Taiwan
}

functions of digital books, children interact with the books directly, listening to the sound effects and playing games. With talking animals and the singing river feature, for example, the whole book comes to life. Kids understand the content more effectively and reinterpret the text with more imagination. These multimedia books encourage children to learn through play and enhance their reading interests [3]. Thus digital books have met the four factors in motivating children to read - the ability to hold a child's attention, to provide enjoyment, playfulness, and a sense of participation. This study not only focuses on how interactive digital books are better than paper books in increasing a child's interest to read, but also on how they motivate children to read after they enter school. This study uses these factors: attention, enjoyment, playfulness, and participation, as four assumption variables to analyze the results. Hopefully, this study will result in helpful information for researchers who are also interested in this topic.

\section{Literature Review}

\subsection{Storybooks and Reading}

In 1985, Shulevitz proposed an idea that storybooks and picture books are two different concepts [4]. Storybooks are based on text to tell the stories and use pictures to enhance the content, but without the detailed depictions of the pictures, readers can still understand the story. The text itself contains no images so pictures play an auxiliary role in a storybook. On the contrary, real picture books rely entirely on images to tell a story. Text appears from time to time as a supporting role to further explain what pictures cannot express. This part can be illustrated through voice, and images are used to fully clarify the story in picture books, or even to replace the text. Therefore, it is possible that with a small amount of text, or even without text, picture books can be "readable." Typically when we tell a story, we say what we see and hear from the story, and that contains a visual reaction for children to imagine their own pictures. Picture books are imagedriven and they are specially made for preverbal kids, who look at pictures and listen to stories. Therefore, they are completely different in concept, and it is about more than the amount of text or pictures. 
Perry Nodelman said, "One picture book contains at least three stories: the story of the words, the story told by the pictures, and the story that comes from combining the two." The pleasure of reading is learning through play [5]. The storybook provides a story-telling platform for children to communicate with their caregiver. Through stories, children get educated mentally and spiritually, and while listening to stories, children can enhance their imagination and cultivate a love of literature. Eric Carle, a famous author of children's books in the United States, once said, "With many of my books I attempt to bridge the gap between home and school." And "The unknown often brings fear with it. In my books I try to counteract this fear, to replace it with a positive message. I believe that children are naturally creative and eager to learn. I want to show them that learning is really both fascinating and fun." Eric Carle wants his picture books to be a reading tool and a toy; to combine these two things together for the concept of learning from play [6].

\subsection{Interactive Books with Digital Pens}

The new kind of interactive digital books allow children to interact with the book; they can hear the voices of animals, the sounds of a river, and even play games that enhance their understanding of what the books contain, and get feedbacks and reinterpretation of the text. The interactive book with a digital pen is a new multimedia book which gives children a fun and enjoyable leaning experience [7]. All of these books have met the four factors which motivate children to read - the ability to hold one's attention, provide enjoyment, playfulness, and a sense of participation. In October 2005, Anoto cooperated with LeapFrog and came out with a new technology called Tag ${ }^{\mathrm{TM}}$ Reading System. This new technology is an interactive book with the combination of a digital pen and a traditional paper book. With the concept of interaction and reading upon pointing the objects, children can practice listening, speaking, and reading. A lot of research has shown that as a child grows, he or she will pay more attention to words and sounds in the books [8]. Children's responses and reactions to new information, and verbal conversation skills are not only related to what they learn in books; children's interactive performances surpass far more than the understanding of the story itself [9].

The key to inspiring children to read is to make reading a pleasant experience. To motivate children to read, building upon on their enthusiasm, questions, and preferences in reading is the best way to maintain their interests in reading [8]. In recent years, interactive books with digital pens have been developed in Japan and South Korea to broaden the world of traditional audiobooks, and to take advantage of memory cards with unlimited hardware space to include diverse sound files, such as vocal sounds, songs, and sound effects. In addition to language learning, China has expanded the use of interactive books with digital pens to other disciplines such as math and biology [10]. In conclusion to the above discussions, this research will be focusing on the content design of the interactive book with digital pens, and to examine each word, character, dialogue, and song in the book to see whether it is pleasurable for children to learn through reading.

\subsection{Reading Interest}

Reading is a dynamic and constructive psychological cognitive process. It is a "decoding process." As many scholars have also pointed out, reading is a total integrative process, which includes affective, perceptual and cognitive functions [11]. Reading is a communicational behavior. Interest is a characteristic of whether or not you like or dislike something and it shows how interested you are in the subject. If you can appreciate, understand, and control an object, then you are interested. Interest is an intrinsic motivation that comes from inside an individual; it refers to a spontaneous demand, and a psychological need [12]. Children use all of their senses to explore various things, in order to attract their attention, visual and audio stimulation are favored. Hence, children's interest in reading can be aroused by sensorial stimulations [13]. However, some research has shown that if a child is exposed to too many multimedia books, a child's attention span will gradually reduce. This can lead to anxiety and loss of concentration; a child is more likely to ignore the narrative part of a book, and slow down in his or her reading ability [10]. Therefore, according to all the research above, the first hypothesis of this experiment will be as follows:

H1: If an interactive digital children's book contains both visual and audio functions, then it will be more attractive than a paper book for children. Early childhood is a stage of play; children play for fun in their daily lives as they grow and develop.

Reading is also considered a playful activity for children. Keeping children interested in reading is one of the most important goals for adults [14], and enjoying what they do is the main way to continue this interest in their daily lives. Some of the researchers examined the relationships between fun, play, learning, and reasoning, and they have found that children learn better when they have fun with what they are doing [8]. An interactive digital book is considered a toy book, its playfulness is different compared to traditional storybooks, as the interactive feature helps to trigger the interest for reading and provides children with a fun experience that engages 
them in the plot. Therefore, according to above points, the second hypothesis of this experiment will be as follows:

H2: Compared to traditional storybooks, interactive digital books provide children with enjoyment and pleasure, so they are better in motivating children to read. In a study on enhancing the chances of children reading by themselves, two researchers Zheng and Zhang found that games based on picture books can help children understand the storyline, increase children's reading comprehension skills, and enrich their learning experiences [15]. Children are not born with an innate love of reading; they need time and catalysts to develop the passion [13]. Because children gain experiences and information from their surroundings through play, games based on the plot of a book will motivate children's reading interests [7] [16]. Games on the back of the books are often very limited by the media device and by certain game rules, so children lose their interest very easily if adults are not initiating the games. Compared with paper books, interactive digital books provide a variety of games that children can play by themselves. Will interactive digital books increase a child's interest in reading? The third hypothesis of this experiment will be as follows:

H3: Interactive digital books are more playful than traditional books, so they are better in enhancing children's interest in reading. Research has found that reading aloud can enhance a child's language development. Via reading in an interesting tone, children are enchanted in the storyline, focus for a much longer time, and their imagination get stimulated. Many studies have found that in reading aloud, it is best to let the children experience the language with an unrelated context. This practice encourages children to recognize sounds that carry meanings, which furthers their imagination [17]. Researchers are encouraging the idea that adults should guide children while reading with them, for example, adults should encourage children to guess what is going to happen in the book before they start, initiate discussions in order to describe information in the pictures, share personal experiences, and relate the story to the child's life in order to attract children's attention. In the process of reading, it is also important to encourage children to ask questions, respond to questions, and predict the story so children are engaged and participated in book reading. By the end of reading, adults should reflect on the story with the children and to add links to their own experiences [8]. The fourth hypothesis will be -- interactive digital books allow children to interact with books using games that encourage participation.
H4: If interactive digital books allow children to interact with books through game playing, then they are better than traditional books in engaging children's participation.

\section{Research Methods}

This study uses the Experimental Method to evaluate 42 second- and third-graders from $\mathrm{Su}$-ao Town, Yi Lan. According to the 2009 Digital Performance Ranking for Taiwanese Individuals, the average score for each city and county is 37.6 , yet $\mathrm{Yi}$ Lan only scored 34.2. from United Marketing Research report at 2010. Among the entire city of Yi Lan, Su-ao town has the biggest number gap and is the first priority in bridging the digital divide of the SME project. The reason why this study is conducted with elementary schools in Su-ao is because children in this town are using fewer digital materials; therefore, the evaluation result will be more reflective than with other children who have been already exposed to digital materials. This assay is divided into the pre-test and post-test. The reliability of the pre-test questionnaire is being tested in 15 elementary schools of the northern region to meet the requirements with an overall reliability of 0.890 . According to the pre-test data analysis, children' reading habits and reading preferences are taken into consideration as they may affect the experimental results, so the questionnaire is designed to test two groups and see whether the results are different. There are twelve questions in the pre-test questionnaire, the $\alpha$ coefficient is .810 for the experimental group, and the control group's $\alpha$ coefficient is .907. An independent sample t test analysis showed that the differences of the two groups in "interest in reading" is not up to the level of significance $(\mathrm{p}=.971>.05)$, so there is no difference between the two groups.

To begin this essay, students were first assigned into two groups of 21 people, one for the experimental group and one for the control group. The students in the experimental group were assigned to read interactive digital books, and students in the control group were assigned to read traditional books. After the students in both groups were given the effective samples, there were 20 and 19 valid completed questionnaires respectively. This study planned to investigate whether digital interactive books can stimulate children's interest and create an impact in reading, so the post-test questionnaires with fourteen questions were designed to examine the four hypotheses, analyze the differences between the two groups, and how the four variables influenced the children's reading interests. The reliability coefficient $\alpha$ was .853 for the experimental group, and .877 for the control group. Both results have met the reliability requirement. When evaluating children's interests in 
picture books from the post-test questionnaires, the mean value of the experimental group was 3.7333, which was higher than the control group (3.0877.) When using the independent sample t-test to analyzes the mean value of these two groups, the results showed that two groups' differences have met the significance level $(\mathrm{p}=.038<.05)$. This study uses an average of all questionnaires as the dependent variable, and four major assumption variables: "attention," “enjoyment," "playfulness," and "participation" as the independent variable. To understand the four variables' impact on reading interests, linear regression analysis was used, the results are shown in the following Table 1:

Table 1. Four variables linear regression analysis summary

\begin{tabular}{|c|c|c|c|c|}
\hline & $\begin{array}{l}\text { Experimental } \\
\text { group }\end{array}$ & $\begin{array}{l}\text { Control } \\
\text { group }\end{array}$ & & All \\
\hline \multirow[t]{2}{*}{ Attention } & $\mathrm{t} \quad 3.445$ & $\mathrm{t} \quad 4.476$ & $t$ & 6.854 \\
\hline & $\mathrm{P} .004 * *$ & P .00I** & $P$ & $.000 * * *$ \\
\hline \multirow[t]{2}{*}{ Enjoyment } & t 5.802 & $\mathrm{t} \quad 2.310$ & $t$ & 6.012 \\
\hline & P. .000 k & P .037* & $P$ & $.000 \%$ * \\
\hline \multirow[t]{2}{*}{ Playfulness } & t $\quad 4.464$ & t 2.651 & $t$ & 5.043 \\
\hline & $\mathrm{P} .000$ * & P .019\% & $P$ & .000 \% \\
\hline \multirow[t]{2}{*}{ Participation } & t 3.674 & t $\quad 5.904$ & $t$ & 7.984 \\
\hline & $\mathrm{P} .002 * *$ & P .000** & p & $.000 * * *$ \\
\hline
\end{tabular}

According to the results above, the four assumption variables "attention," "enjoyment," "playfulness," and "participation" are up to a significance level for the impact on reading interest. The experimental group and the four major assumption variables are "very significantly" above the average, thus these four variables have influence on reading interests.

\section{Data Analysis}

This study uses the average of all questionnaires as the dependent variable, and four major assumption variables: "attention," "enjoyment," "playfulness," and "participation" as the independent variable. According to the results of the table above, these four assumption variables, "attention," "enjoyment," "playfulness," and "participation" have significant impact on children's reading interests, especially for the experimental group. Through an independent sample $t$ test, the differences of the two groups have reached a significant level, and the same questions were extracted out in the pre-test and post-test to view the progressing scores using an analysis of variance. The data below showcases each of the four hypotheses:

Unlike traditional story books, images and sound in interactive digital books cause differences in children's attention span. According to the linear regression analysis of the data results, interactive digital books caused children's attention on reading interest to reach a significant level. (All $\mathrm{p}=.000<.001$, Experimental group $\mathrm{p}=.004<.01$, Control group $\mathrm{p}=.001<.01)$ However, to look at the independent sample t test analysis from both groups, and considering the use of different picture books, the mean value of the experimental group (4.1333) is higher than the control group (3.2632). Based on the results, interactive digital books are more attractive than traditional books for children. The two groups' differences have met the significance level $(p=.001<.05)$. This result supports hypothesis H1, "If an interactive digital children's book has both visual and audio functions, then it will be more attractive than a paper book for children." External stimulus such as visual and auditory cues are better in drawing children's attention [15]. Thus, interactive digital books used in the experimental group have been proven to provide a better result in drawing children's attention.

Unlike traditional story books, interactive digital books provide enjoyment and contribute to differences in children's reading interests. The level of enjoyment of storybooks has reached a significant level in children's reading interests (All $\mathrm{p}=000<.001$, experimental group $\mathrm{p}=000<.001$, control group $\mathrm{p}=.037<.05$ ). The mean value of the experimental group is 3.8866, and the control group is 3.2107. The outcome shows that interactive digital books are better than traditional books in giving children reading enjoyment and pleasure with a significance level of $\mathrm{p}=.021<.05$. Therefore, hypothesis $\mathrm{H} 2$, "Compared to traditional storybooks, interactive digital books provide children with enjoyment and pleasure, so they are better in motivating children's interests in reading," is valid. According to many scholars, childhood is a period of joy and pleasure, so any playful books are considered attractive to children. The most effective way to encourage children to read is to start with books that are easy to read [18]. In terms of enjoyment level, the experimental group who played with interactive digital books had a higher score. Unlike traditional story books, the playability of interactive digital books create differences in children's reading interests. The P-values of the results have met the significance level (total $\mathrm{p}=.000<.001$, experimental group $\mathrm{p}=.000<.001$, control group $\mathrm{p}=.019<.01$ ). Based on the average score, playability plays a key role in increasing children's reading interests. The mean value of the experimental group is 3.8500, which is higher than the control group (3.3421). However, this data is not up to the level of significance $(\mathrm{p}=.143<.05)$. Therefore, hypothesis H3 "Interactive digital books are more playful than traditional books, so they are better in enhancing children's interest in reading" is invalid. According to many research findings, books with extended games can enhance children's reading interests [7]. While interactive digital books are more entertaining 
than traditional books, they are no better in increasing children's reading interests than traditional books. To further discuss the playful aspect, an in-depth understanding and analysis is needed on the linkage between games and storylines, and how the game is played. To compare with the traditional story books, interactive digital books come with interactive and game learning mechanisms which give children a sense of participation. According to the linear regression results (All $\mathrm{p}=002<.01$, experimental group $\mathrm{p}=000<.001$, control group $\mathrm{p}=.000<.001$ ), a sense of participation has a significant impact on children's interest in reading. The mean value of the experimental group (3.5832) is higher than the control group (32.9121), which shows that interactive digital books are better than traditional books in engaging children's participation. Based on the analysis of the independent sample's T-test result, the differences of the two have met the significance level $(\mathrm{p}=.028<.05)$. This outcome proves that the fourth hypothesis "If interactive digital books allow children to interact with books through game-playing, then they will be better than traditional books in engaging children's participation." is true. Reading aloud helps children to get into the storyline, and generates a sense of participation [30]. In addition, children's readings interests are influenced by the functionality of interactive digital books. The following table is the analysis of four variables - "attention," "enjoyment," "playfulness," and "participation" and the overall preferences of the independent sample t-test.

Table 2. Comparsion independent T-test of experimental group and control group

\begin{tabular}{|l|l|l|l|l|}
\hline & $\begin{array}{l}\text { Average } \\
\text { Deviation }\end{array}$ & $\begin{array}{l}\text { Standard } \\
\text { Deviation }\end{array}$ & $\mathrm{t}$ & $\mathrm{P}$ \\
\hline Attention & .87018 & .24700 & 3.523 & $.001 * *$ \\
\hline Enjoyment & .67263 & .27813 & 2.418 & $.02 I^{*}$ \\
\hline Playfulness & .50789 & .33960 & 1.496 & .143 \\
\hline Participation & .67106 & $.2924 \mathrm{I}$ & 2.295 & $.028 *$ \\
\hline $\begin{array}{l}\text { Total } \\
\text { Preference }\end{array}$ & .64561 & .30045 & 2.149 & $.038 *$ \\
\hline Total Score & 9.59474 & 3.21226 & 2.987 & $.005 * *$ \\
\hline
\end{tabular}

The same eight questions in the pre-test and posttest questionnaires are isolated and the progressing average scores are to be further analyzed. The progressing average scores of the experimental group have proven that interactive digital reading can improve a child's interest in reading, however, for the control group, the average scores have slipped, the reason could be children are less attracted to traditional reading materials. According to the Jen \& Hsu's study, children like books full of rich content, such as pop-up books and toy books, etc [20]. Children's books are more diverse these days, so traditional picture books are slightly inferior than before. This result also reflects that for children at this age, their interests in reading have declined for regular books [19]. Therefore, it is worthwhile to further understand the content design of interactive digital books in the area of children's learning.

\section{Discussion}

An interactive digital book combines the features of an audiobook and the characteristics of a storybook, this unique entertaining concept plays out in many emerging products. This study explores both visual and auditory sensory characteristics in order to understand the impact on children's interests in reading. The conclusions of this study, the four factors - attention, enjoyment, playfulness, and participation play major roles in motivating children to read, and echo the results of previous literatures [14] [16].

An interactive digital children's book contains both visual and audio functions, and will attract children's attention more so than a paper book. Children use all of their senses, relying especially on visual and audio stimulations to explore various things that attract their attention; and storybooks are still very popular in the children's book category because of their rich visual elements [16]. Interactive digital books are considered children's books; with interactive functions to engage children through touches and sounds, children can search for words and pictures to the sounds they hear, or search for more interactive functions. Such processes allow children to pay more attention to the books, and also increase their reading interests. At the end of the experiment, some children even requested to read more of these books. Therefore, the design of interactive digital books has great potential in the future.

Interactive digital books are entertaining; they help to develop children's interests in reading. A study in Japan points out that interactive books are more charming for children [20]. In the experiment, the two groups showed visibly different reading interests. The children in the control group who were not interested in reading books got tired of reading very easily and even closed the book to play with other children. The children in the experimental group who were not interested in reading books were still going through the book, playing with the tag-pen and waiting for new responses. In the results' fun and entertainment portion, this experiment showed that the experimental group with interactive digital books scored higher than the control group with traditional storybooks. Therefore, to inject fun into book reading has a positive influence on reading, and is worth thinking about as a design direction. 
The playability of interactive digital books did not help to enhance children's reading interests. The research has shown that a game based on the plot of a book will motivate a child's reading interest, but games that are on the back of traditional books are very limited and often require adults' interventions to keep children's interest [7] [15] [17]. The combination of a digital point reading pen and a detectable chip device have brought interactive digital books to life. The score of the experimental group was higher than the control group who read the traditional story books, but the difference was not up to the level of significance. This experiment was using an AZUR tag-pen manufactured by Soho Network Co. LTD (see Figure 1). The function of this tag-pen is limited to pointing, reading, and translating only. It does not provide a variety of games for children to play, which is why when compared with traditional books it does not show any significant difference in encouraging interest.

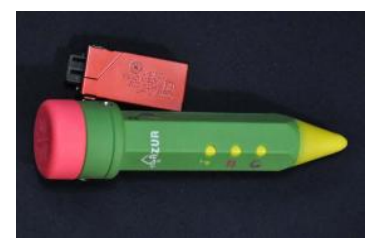

Figure 1: AZUR tag-pen with interactive digital book

However, the mean value of the experimental group is higher than the control group which shows interactive digital book could still be better than traditional books in providing fun and playable games. The interactive books bring the pictures to life, and the process of reading, for children is a play, story book is not only a book, children could really interact with it, you can hear the voice when you read, tag the words and pictures, this process not only fun but also experiencing the situation themselves, reading makes children happier. This result shows that children like to play games based on the plot of a book, however, the games must be fun and have a variety of choices to attract children's attention. When integrated with new technologies in the game design project, designers should keep in mind on what children can learn and how to increase children's reading interests (see Figure 2).

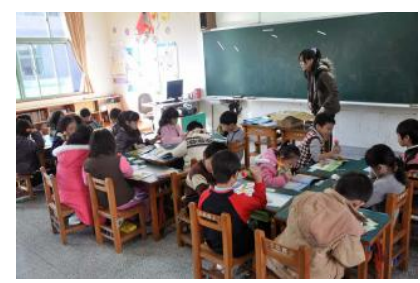

Figure 2: Post-test in Experimental Group
Interactive digital books come with interactive and game-learning mechanisms which give children a sense of participation. Reading aloud is one of the reading styles initiated by parents. During reading, parents interact with children to keep children's attention on the book as well as to participate in the discussions [14] [19]. The experimental group's mean value of participation is higher than the control group which means children enjoy listening to the story while reading, before they enter the early independent-reading phase. Therefore, interactive digital books are better than traditional books in helping children to read when they are not ready to read by themselves.

From in-depth interviews with education sector experts, many teachers believe that children's curriculums are overly dynamic; although the parents are more willing to buy such materials, they may have negative an impact on children. Unlike most ebooks, an interactive digital book is still a paper book, so the parents do not have to worry about prolonged computer usage. With a digital pointing pen, paper books can also perform simple interactive functions and voice feedbacks that attract children. The result has shown that children enjoy reading more when reading interactive digital books.

The result of this quantitative experiment shows that children have higher motivation in reading interactive digital books. Children, through their innate senses, are more attracted to the visual, audio, and tactile sensations of leafing through an interactive digital book. The process of reading an interactive digital book is like playing, the book provides children with a fun, enjoyable, and handson reading experience, while the digital pointing pen brings the content to life. The whole process is not only interesting, but it makes children happy.

\section{Conclusion}

Reading is a dynamic and constructive process. In order to make sense of the text, readers need to build ideas from words alone, and form ideas about what is in the book. An interactive digital book is an edutaining product, which combines the characteristics of audiobooks and storybooks, both visual and auditory sensory characteristics, to stimulate children's reading interests. From this research has shown that there are four important factors that play a major trigger in motivating children to read. These factors include playfulness, the ability to hold the child's attention, provide enjoyment, and allows for participation. Unlike traditional story books, digital interactive books provide colorful pictures, enjoyable sound effects, and interactive actions that satisfy all four of these factors. These factors are also the biggest quality in digital reading. The research reveals, the children's story books with digital pen raise more reading 
interest for children than traditional story books, and attract more attention as well; they also provide more joyfulness, recreation; reading through audio, tag and read function could bring children participation. Overall the analyses, children are more interested in children's story books with digital pen than traditional story books, which means these factors are one of the important part to cultivate children's reading interest, if applies well to learning material, which could help children cross the transition of reading type change.

However, there are still questions for the education sector and commercial industries to address, such as how to initiate children's interests in books, create more imagination, and motivate selflearning to enhance children's active reading habits. Reading is an important skill for everyone. There must be a bridge between children and books for children to regain interest in reading, and foster attention, enjoyment, playfulness, and participation characteristics in reading. Parents, educators, authors, and publishers should work together to create books, either traditional or digital, to make reading fun and enjoyable for children. As a caveat, researchers are still trying to find out what specific factors create the most attractive books for children. Currently, only a few domestic and foreign researchers have conducted studies on the influence of interactive digital books on a child's reading interest, so this is still a relatively untouched area worth exploring.

\section{References}

[1] McKeown, M. G., \& Beck, I. L., "Encouraging young children's language interactions with stories", In D. K. Dickinson \& S. B. Neuman (Eds.), Handbook of early literacy research, 2, Guilford, New York, 2006.

[2] Li, D., How to guide students to read, Hungyeh Publishing, Taipei, 2006.

[3] Luo, Y., "The production of digital code products", Printing Technology, Guang Zhou Printing Factory Co., Kwong Chau, 2009, pp. 51-52.

[4] Shulevitz, Uri, Writing with pictures, Watson-Guptill Publications, New York, 1985.

[5] Nodelman, P. \& Reimer, M., The Pleasures of Children's Literature, Allyn \& Bacon, London, 2002.

[6] Carle, E., The Art of Eric Carle, Philomel Books, NY, 2002.

[7] Stern, K., "Play me a story: Games based on children's books", Teacher Librarian, Bowie, 2007, pp. 30-34.

[8] Morris, D., Bloodgood, J. W., Lomax, R. G., \& Perney,
J., "Developmental steps in learning to read: A longitudinal study in kindergarten and first grade", Reading Research Quarterly, 38(3), 2003, pp. 302-328.

[9] Justice, L. M., \& Ezell, H. K., "Use of storybook reading to increase print awareness in at-risk children", American Journal of Speech-Language Pathology, 11(1), 2002, pp. 17-29.

[10] Jen, H. \& Hsu, M. C., "The study of interactive books for basic English learning", 6th International WOCMAT \& New Media conference, Taoyuan, 2010.

[11] Goodman, Kenneth S., On Reading, Heinemann, NH, 1996.

[12] Worthy, J., "Patterson, E., Salas, R., Prater, S., \& Turner, M., More than just reading: The human factor in reaching resistant", Reading Research \& Instruction, 41, 2002, pp. 177-202.

[13] Guthrie, J. T., Hoa, L. W., Wigfield, A., Tonks, S. M., \& Perencevich, K. C., "From spark to fire: Can situational reading interest lead to long-term reading motivation?", Reading Research and Instruction, College Reading Association, Provo, 2006, pp. 91-117.

[14] Gross, J., Make your child a lifelong reader, Tarcher, New York, 1986.

[15] Zheng \& Zhang, "An action research of applying picture books in nurturing multiple intelligences of young children", Bulletin of Chung Hwa College of Medical Technology, 22, Tainan, 2005, pp. 37-56.

[16] Lin, M. Y., Appreciation and application of picture books, Psychological Publishing, Taipei, 2000.

[17] Snow, C.E., Tabors, P.O., Nicholson, P.A., \&Kurland, BF., "SHELL: Oral language and early literacy

skills in kindergarten amd first-grade children", Journal of Research in Childhood Education, Olney, 1995. pp. 37-48.

[18] Dix, A., Being playful-learning from children, Interaction design and children conference, Preston, 2003.

[19] McGee, M. L., “Talking about books with young children. book talk and beyond: Children and teachers respond to literature", International Reading Association, Newark, 1995, pp. 105-115.

[20] Nakakoji, Saito, Osakabe, Toda, Akita \& Iwata., "The design of the dynamic clothing picture-book-using the conductive fabric for picture-book study reflection. Report of research of information Processing Society, Entertainment computing(18), 2007, pp. 33-40. 